This is a self-archived version of an original article. This version may differ from the original in pagination and typographic details.

Author(s): Valo, Maarit; Sivunen, Anu

Title: Future Directions in Workplace Communication

Year: 2020

Version: Accepted version (Final draft)

Copyright: (c) 2020 Taylor \& Francis

Rights: In Copyright

Rights url: http://rightsstatements.org/page/lnC/1.0/?language=en

Please cite the original version:

Valo, M., \& Sivunen, A. (2020). Future Directions in Workplace Communication. In L. Mikkola, \& M. Valo (Eds.), Workplace Communication (pp. 193-206). Routledge.

https://doi.org/10.4324/9780429196881-15 


\title{
15 Future Directions in Workplace Communication
}

\section{Maarit Valo and Anu Sivunen}

\begin{abstract}
Various utopias and dystopias about the significance of human communication in the future workplace have been presented. Artificial intelligence (AI) will undoubtedly be one of the most remarkable influences on future work, and employees must prepare themselves to have social robots as coworkers. Partly as a result of the increased use of AI, various forms of selfemployment will gain ground. Lifelong occupations and professions will be less common, and the value of one's ever-evolving skills and knowledge, applicable to diverse work contexts, will consequently receive more emphasis. Knowledge work will increasingly take place in digital communication environments, and telework and other forms of flexible work will continue to grow in popularity. Because communication between people is indispensable, there will always be human work that cannot be automated. Interpersonal work will remain essential. Proficiency in interpersonal and team communication will definitely be a key asset for anyone working under changing circumstances, in varying contexts, and with diverse colleagues. The development of communication competence and the learning of interpersonal skills are vital for future work.
\end{abstract}

Keywords: artificial intelligence, human-robot interaction, interpersonal work, selfemployment, working life, workplace communication

\section{Introduction}

Working life has changed radically during the last few decades, largely due to globalization and digitalization, including mobile services. Artificial intelligence (AI) and robotization intelligent computers or digital robots with the capability of reacting, learning, and working like humans and performing tasks usually associated with human intelligence - have emerged as a robust means of facilitating work processes. Such powerful factors will continue to have a serious influence on working life and on workplace communication in the future. 
In today's workplace, interpersonal and team communication competences are vital. Knowledge work largely relies on interpersonal relationships maintained both face-to-face and in technology-mediated ways. Already now, employees' ever-evolving communication knowledge and skills, applicable to diverse work contexts, are their key assets in the fastchanging and challenging labor market. In the future working life, lifelong occupations and professions will be less frequent, and consequently, generic proficiency, as in interpersonal and team communication, will receive more emphasis. Because communication between people is indispensable, there will always be interpersonal work. Under changing circumstances, in varying work contexts, and in dissimilar work communities with diverse leaders and peer coworkers, interpersonal communication competence will be the principal resource for everyone.

Many utopias and dystopias about the significance of human communication in the future workplace have been presented. For example, will human beings still be required for work? To what extent will knowledge work be robotized? What will future workplace communication be like? Will we have to learn to communicate with robots in our everyday work?

Naturally, predicting the future of work and the changes in our communication processes at work is a major challenge, because circumstances and working conditions differ from country to country and in occupations. Labor legislation, employment regulations, organizational hierarchy, and employee participation, as well as leadership and management practices, take different forms today and will continue to do so in the future. However, some general indications regarding knowledge work can be identified and their impact on communication in the workplace anticipated.

This chapter aims to explore major trends in the future of working life and envisage the role of human communication in future workplaces. First, the future of working life is explored. The goal is to provide an understanding of the societal changes in work and employment, mostly caused by the advance of AI and robotization. Both new kinds of work and new forms of selfemployment will emerge. However, human competence and interpersonal work will remain strong in areas where they cannot be replaced or are chosen to be invaluable. Second, future trends in workplace communication are introduced. Due to globalization and internationalization, diversity in the workplace will increase. Various types of flexible work arrangements will continue to grow in popularity. Digital communication environments and 
practices will be enhanced, and employees will have to learn skills in human-robot interaction. However, human cooperation and interpersonal relationships will persist, as humans are better at adapting to complex and changing communication situations.

\section{The Future of Working Life}

The future of working life is characterized by pertinent major developments that are strongly intertwined. AI will certainly be one of the most remarkable influences on future work. Partly as a result of the increased use of AI, various forms of self-employment will increase (World Economic Forum 2018). Stable and even lifelong occupations and professions will be less common, and the value of one's skills and knowledge that is applicable to diverse work contexts will consequently receive greater emphasis. However, because communication between people is indispensable, interpersonal work will remain significant.

\section{Artificial Intelligence Leads to Changes in Employment}

AI can be defined as “a system's ability to interpret external data correctly, to learn from such data, and to use those learnings to achieve specific goals and tasks through flexible adaptation” (Kaplan \& Haenlein 2019, 17). It has been predicted that many of the jobs that exist today will become obsolete due to the advance of AI and roboticization. Estimates of the number of jobs that will disappear vary widely, depending on the scenarios of economic and technological development and political landscapes in the near future. For example, the estimates for vanishing jobs in the United States range from 9 percent to 47 percent of those existing today (Estlund 2018).

Computers and robots can take over routine and repetitive work from humans. Manufacturing, maintenance, accommodation and food services, traffic and transportation, and construction work, for example, include procedures that have already been automated. AI can also support routine office work when tasks involve surveillance, control, and monitoring, such as making service timetables, managing budgets, or checking accounts. With the arrival of Big Data, robots can plan, optimize, organize, and coordinate a large number of tasks faster, with much more accuracy and reliability than humans. 
However, in the past few years, it has become apparent that AI can also outperform humans in many high-skilled activities (Kaplan \& Haenlein 2019; McKinsey Global Institute 2017). Robots are being trained to perform cognitive tasks: Natural language processing, searching and analyzing information, logical reasoning and problem-solving, and making judgments and decisions. Consequently, robotization will not be limited to the area of routine or even skilled work. Robots are predicted to become increasingly capable of evaluation, reasoning, and even socio-emotional sensing. They can also be made to learn humanlike interaction skills in real interactions with people (Qureshi, Nakamura, Yoshikawa, \& Ishiguro 2018). Thus, AI will presumably encompass parts of professional knowledge work (Estlund 2018; McKinsey Global Institute 2017). Still, changes in knowledge work may be less about job disappearance than about job transformation; employees will need to adapt their roles and skills as they work alongside increasingly capable robots and AI (Healy, Nicholson, \& Parker 2017). Similarly, forms of social interaction that require human capabilities, such as high-level creativity, critical but innovative thinking, the exchange of ideas, argumentation, and complex decision-making, will remain crucially important human attributes.

Even though robots will at first have limited capabilities compared to humans, their presence will inevitably cause quantitative and qualitative changes in employment over time. According to the World Economic Forum (2018), an extensive number of job holders will be made redundant due to the new division of labor between humans and machines. However, alongside pessimistic views about robotization causing unemployment, more positive prospects have recently emerged. Certain sectors and professions are predicted to have lower automation potential. These include education, training and development, social assistance, and professions in law, health care, executive management, art, culture, and design (Estlund 2018; McKinsey Global Institute 2017). In the immediate future these fields will still mostly rely on human communication and input.

The reshaping of the work landscape will generate new kinds of work, in which social interaction and cooperation with people will certainly be needed to nurture creativity and innovation. According to recent optimistic hypotheses, new forms of creative work will emerge when work is further automated. Automation will lead to new areas of economic activity and bring about novel jobs created by new technologies (Morikawa 2017). These may include specialists in AI, Big Data and robotics, information security, user experience, and humanmachine interaction, as well as other experts on the interface between humans and machines 
(World Economic Forum 2018). For example, future work in robotics may encompass designing and training robots to participate in multifaceted work environments and to perform increasingly complex tasks, often together with humans.

Automation and robotics have led to political debates about a universal basic income, possibly guaranteed for everyone but especially for those losing their jobs because of automation (Amadeo 2019; Levin-Waldman 2018). Several initiatives have already been launched and experiments carried out in regard of basic income in various parts of the world. If basic financial needs can be fulfilled for people in the future, the purpose of work is predicted to shift from earning a living to self-actualization, pleasure, and dignity (The Millennium Project 2019). Scenarios like this would profoundly change people’s work life and have substantial effects on societies as well.

\section{Increases in Self-employment}

In the future world of work, employment relationships will be based to a large extent on temporary projects and contracts. Freelancing, microwork, diverse new entrepreneurial models, and various other types of self-employment will increase (World Economic Forum 2018). This trend will be reinforced by information and communication technology (ICT), which will continue to enable working from home or other places of the worker's choice. Selfemployed professionals are highly dependent on communications technology (Eurofound and the International Labour Office 2017), which allows them to maintain their contacts with others working in the same field.

A new type of self-employment for professionals is platform work (Eurofound 2018). In this kind of work, individuals or organizations seek and provide paid services through online platforms. Professional tasks can include educational services, software development, graphic design, or marketing and communication. On-demand platform work is predicted to increase rapidly across labor markets in the future (ibid., 62).

All types of self-employment entail individual responsibility for continuing education, lifelong learning, and career development (World Economic Forum 2018). Self-employed workers must also arrange their own health care and pension as well as plans for potential unemployment. These forms of social security have to be accessible in some way to all 
employees, including the self-employed, if work is to remain sustainable in the future (Eurofound 2018). The sustainability of work (Eurofound 2015) refers to job characteristics and working conditions that support people throughout their working life, until retirement age. Promoting longer working lives is, after all, one of the major goals of today's societies. Sustainable work promotes mental and physical health, inclusion, motivation, productivity, and sense of meaningfulness over the life course. Because human contacts are one of the key benefits of having a job, sustainable work should foster communication between people.

To an increasing number of people, future work will involve various entrepreneurial, selfemployed, and worker-initiated activities. With few permanent, fixed-term, or part-time contracts, people engaged in such activities will work either independently or through online platforms, in loose networks or communities. Platform workers rarely have strong interpersonal relationships with other workers, representatives of the platform, or their clients (Eurofound 2018, 28-30). History will determine whether loose ties with other workers can satisfy their communication needs. In today's workplace, new employees usually want to identify themselves with their coworkers and the whole work community. But what will employees identify with if there is no organization and no workplace - and if there are no other people whom they can call workmates or colleagues? Will the mission of the work become the crucial factor in one's identification? Or might the identification with one's own expertise, career, or experience come to replace the commitment to specific organizations and workplaces?

\section{From Professions and Occupations to Skills and Knowledge}

A few decades ago, the nature of professionalism was still quite self-evident. Professions were high-status occupations with high-level qualifications, restricted entry, science-based specialized knowledge, and substantial independence (Dent, Bourgeault, Denis, \& Kuhlmann 2016). Typical professionals are doctors, lawyers, teachers, university professors, nurses, engineers, and social workers. However, professions have been subject to changes due to privatization, internationalization, and other political, societal, and economic developments (Evetts 2011). In organizational settings, professionals have lost some of their independence and have had to adjust to workplace rules and requirements (Vogd 2017). This development has shifted professional communication toward joint planning and collaborative decisionmaking in institutional workplaces. 
Besides the changes that have taken place in traditional professions, novel forms of professional expertise have emerged. In recent decades, technological advances, especially in ICT, have led to the rise of new professional groups with expert knowledge than can be applied in various contexts in working life. Agevall and Olofsson (2013) have called these professionals “employees of the knowledge society”. Moreover, Hearn, Biese, Choroszewicz and Husu $(2016,68)$ have emphasized the impact of ICT on professional work, suggesting that ICT will give rise to new kinds of professionals with expertise on the interface between humans and various forms of technology. In addition to ICT professions, the new professions include human resource consultants, specialized managers, and communication professionals, such as interpersonal communication consultants, specialized journalists, and public relations experts (Brante 2013; Evetts 2011).

What is the future of specific professions and clearly defined occupations? Public discussion has suggested a large number of fictional job titles of the future: Innovator, humanizer, inspirer, social connector, change promoter, exclusion preventer, mental flexibility coach, art guru. However, specific occupations with innovative titles might not be the new direction in working life. Instead of preparing themselves for particular occupations, workers will increasingly make use of their generic competencies. These broad abilities are not tied to defined occupations but can be applied to many fields, industries, sectors, or subsectors. Workers will not necessarily need to "switch to a new occupation", instead, they will need to continually adjust and apply their competence to various work tasks over their life course. One’s working competence can take on different emphases over the course of one's career. The change in the emphasis of working competence will often alter the focus of communication competence. New social environments bring about different interaction challenges.

Nevertheless, future professionals are almost always expected to possess T-shaped knowledge and expertise. T-shaped skills were first described by Guest (1991) almost three decades ago (Ing 2008). The stem of the T represents deep, specialized knowledge in a particular area, whereas the top of the T represents broad, diversified competencies - possibly also from other fields - that can be used to deal with versatile contexts and problems at work. This broad perspective on employee competence also encompasses social and communication skills as well as diverse active networks of professionals and organizations. According to Barile, Saviano, and Simone (2015), the knowledge economy demands that all actors - not only 
individuals but also organizations and communities - gain a set of T-shaped competencies in the future.

\section{Significance of Interpersonal Work}

Interpersonal work will continue to play a central role in the future. There will always be human work that cannot be automated. According to the McKinsey Global Institute (2017), the humanto-human perspective is needed, for example, in leadership, development, innovation, creativity, decision-making, social problem-solving, and interaction with stakeholders (customers, suppliers, the public). In fact, interpersonal work will gain even more significance, because humans will need to jointly decide what they want the AI to do and how to exert control over its work. Naturally, moral, ethical, and political questions will remain human considerations.

Interpersonal communication plays an important part in many predictions regarding the work of the future. Future work can even be characterized as significant and meaningful interaction between interdependent people in networks and communities. Although face-to-face presence in workplaces will become less necessary, workers will still need connections to other people, and this kind of presence can be gained by means of communication technology (Kilpi 2016). Online collaboration will be one of the most important competencies for workers in the future (Moore 2016). Work that relies on interpersonal communication will remain significant, as interpersonal contacts, whether face-to-face or via technology, are needed for discussion, deliberation, and collaboration between people. Interpersonal communication is needed also in public and private services, because clients expect more individual and personalized services from them.

Furthermore, interpersonal work will be based on human competences that can hardly or never be taught to machines. Even though robots can take care of complicated work tasks, they lack the capacity of adapting or accommodating themselves to differing contexts or situations. They are mostly designed for singular performances (Edwards, Edwards, Westerman, \& Spence 2019). Only we humans are able to position and orientate ourselves in specific communication settings and roles and to flexibly move from one interaction to the next. Even though empathic behaviors - inferring users' affective states and reacting to them - can be taught to robots (Leite et al. 2013), it is genuinely a human skill to be able to target messages at different partners and 
audiences. Perspective-taking (seeing the situation from the other person's perspective) and other-orientedness (adapting one's communication behavior to the other person) also belong solely to human communication competence.

\section{Future Trends in Workplace Communication}

When mobile ICT emerged in knowledge work and enabled employees to accomplish their tasks from any location outside the workplace, it was predicted that all employees would some day work remotely. This has not yet happened; in the majority of knowledge jobs, remote work or telework is still the secondary way of working (Eurofound and the International Labour Office 2017). However, telework will most likely continue to grow in popularity.

The increasing number of self-employed people indicates the growth of mobile and flexible work without specific workplace locations. Project- and platform-based work will be ever more multilocational and technology-mediated, not tied to any time or place. Work will be carried out in various distributed contexts, often with changing colleagues. Teams will have nonpermanent members who share their input with other teams as well. Multiple team membership and flexible team boundaries will become more commonplace (O’Leary, Mortensen, \& Woolley 2011). Indeed, one of the demands placed on future workers will be the social and communicative ability to work in short-term, and often distributed, teams and projects.

\section{Digital Communication Practices in the Workplace}

In new types of work arrangements, the use of communication technology has become essential. Communication with colleagues and team members will increasingly take place in a digital communication environment, whether via email, instant messaging, or video conferences, via internal or public social media, or via novel interactive applications that do not yet exist. Such technologies enable distributed workers to be connected to one another and feel socially present despite their geographical separation. At the same time, the technologies create constant interruptions in the form of notifications and messages sent by collaborators (Fonner \& Roloff 2012). Status cues provided by these technologies can also make it more challenging to "go invisible” (Gibbs, Rozaidi, \& Eisenberg 2013) by logging out of the platform or restricting one's availability to others when focused working time is necessary. 
Thus, in order to effectively collaborate via various digital communication technologies, dispersed workers need to increasingly manage the balance between constant connectivity with others and focused, solitary work. The benefits of both communication technologies and geographic and temporal dispersion have to be used in an optimal way. This balancing requires negotiation about the communication tools that suit the collaboration (Ruppel, Gong, \& Tworoger 2013. It also requires negotiation about how and when dispersed colleagues can and should be contacted and which communication technology offers the best communication channels (video, audio, or synchronous or asynchronous text channels) for a given purpose (Sivunen \& Valo 2010).

Furthermore, public social media and enterprise social media platforms have entered the workplace. They have made communication between colleagues and teams in and across organizational boundaries even more complex and ubiquitous than before. It can be anticipated that novel digital environments will be developed for and applied to various forms of future professional work. For example, AI will be integrated into the workplace in many ways. AI can facilitate communication on digital platforms by helping employees decrease their repetitive communication duties. AI is able to send reminder alerts and provide automated responses to emails or other modes of interaction. It can also organize and schedule tasks and suggest priorities. Thus, AI will be used to allow employees to focus their attention on more complicated issues (Phillips 2018). The complicated issues tend to be the most communicationintensive ones, requiring concerted interpersonal and team interaction.

In an increasingly globalized world, digital communication technologies and practices can help dispersed workers save travel costs and carbon footprints and enable them to collaborate more effectively from afar. The successful implementation and use of these technologies could reduce business travel, which could have a favorable impact on the environment and organizations' sustainability. However, policies, regulations, and incentives will also be required to make digital communication practices the preferred way to collaborate instead of traveling for short face-to-face meetings.

\section{Human-Robot Interaction}


Both AI and robots already belong to working life in many fields. AI is mainly used in routine information work, whereas robots can perform difficult or dangerous physical labor for humans, for example, in manufacturing and healthcare (Robots and the workplace of the future 2018). Robots come in versatile forms: They may be machine-like, somewhat anthropomorphic, human-like, and even ultra-realistically human-like (Piçarra \& Giger 2018; Vlachos, Jochum, \& Demers 2016). If robots are modeled strongly on human beings, they may communicate through touch, sound, speech, gestures, facial expressions, and gaze. Robots then become social robots. They are designed to communicate with humans and be our interaction partners.

Social robots have been found to cause feelings of uncertainty, unease, or eeriness in people who engage or expect to engage in actual interactions with them (Edwards, Edwards, Spence, \& Westerman 2016; Quadflieg, Ul-Haq, \& Mavridis 2016). Nevertheless, among people who find human-robot interaction useful, engagement with social robots can prove to feel meaningful and reactions to them can be very positive (Khosla, Nguyen, \& Chu 2017).

Interestingly, people tend to consider social robots as social actors. This is known on the basis of the reactions and attributions by people conversing with them. (de Graaf, Allouch, \& Klamer 2015, Edwards et al. 2019.) In fact, people interact with social robots and respond to them as if they were other people. People also apply similar social rules and interaction scripts when communicating with robots as when talking to people. This line of thinking by Nass and Moon (2000) or Reeves and Nass (1996) is called Computers Are Social Actors (CASA). Therefore, when preparing to welcome social robots as coworkers in the future workplace, employees should ensure that they have the necessary communication competences. The very same interpersonal communication skills that we need with our coworkers today are predicted to be essential also when interacting with robots.

In the future, robots will first act as assistants and advisers to humans, but gradually they may also work alongside humans even in independent roles - for instance, as negotiators (Stoll, Edwards, \& Edwards 2016) or teammates (Beans 2018). Thus far, few workers have had personal experience with human-like social robots, and this lack of familiarity may certainly contribute to their current feelings of unease and hesitation (Gnambs \& Appel 2019). However, according to present knowledge, people generally express positive attitudes toward robots in various fields of work, and they consider robots appropriate for versatile tasks in the workplace 
(Savela, Turja, \& Oksanen 2018). Workplace attitudes are predicted to become more robotfriendly in the future, provided that people gain experience with social robots and, in particular, perceive them as beneficial (Edwards et al. 2019).

\section{Communication in Contexts of Diversity}

Diversity in the workplace has increased as a result of globalization and internationalization. Today's knowledge work has brought together people with different national and ethnic backgrounds as well as different language, gender, and age identities. In workplaces, human diversity is likely to increase in the coming decades.

Interpersonal communication always involves perceptions of the other person. Because such perceptions are either pre-existing or arise in the initial interaction, before further communication takes place, they can be powerful. Generalizations about and judgments of workmates made on the basis of their salient group memberships may take the form of a prejudice that can be harmful in interpersonal communication (Harwood 2017). Prejudices may even lead to distrust, inequality, and discrimination in the workplace if not managed successfully.

In intergenerational communication, for example, expectations based on age group can be misleading. Younger or older workers are not homogenous groups of people but individuals with various levels of knowledge and skills. “The digital generation” refers to a uniform age cohort (Bennett, Maton, \& Kervin 2008), but it can also be used as a playful moniker for people who do not necessarily belong to the same age group but share a keen interest or good skills in communication technology. In the future, the knowledge level of technology-mediated communication throughout the life span will be higher than it is today, and it cannot be presumed to be based on age.

\section{Cooperation and Coopetition}

Cooperation will be a key element of future work in any field. Global strategic networks and innovation clusters are built to promote financing, exports, and marketing. Networked collaboration across organizational boundaries has already become a common way of organizing work. Networks are now and will always be based on interpersonal relationships. 
Their success depends on the communication abilities of the people participating in them. Productive networking requires the efficient use of communication technology, active involvement, and good interpersonal skills. Multiprofessional cooperation and leadership for multiprofessional teams and networks will be needed in the future.

Today's entrepreneurship is not only about competition. With increasing frequency, small and medium-sized enterprises as well as start-ups are establishing joint networks for cooperative work in areas such as marketing. Cooperation with competitors or in competitive circumstances is called coopetition (Ghobadi \& D’Ambra 2011). In the future, coopetition is very likely to increase.

\section{Importance of Interpersonal Communication at Work}

In future knowledge work, the capacity for effective interpersonal and team communication under changing circumstances, in varying contexts, and with diverse colleagues will definitely be a key asset for everyone involved. Both the Organisation for Economic Co-operation and Development (OECD 2018) and the World Economic Forum (2016) have described the essential competencies needed in twenty-first-century working life. These competencies are generic, that is, applicable to a large number of skilled and professional work contexts. The competencies include a wide variety of skills that are crucial components in interpersonal and group communication: Engagement, information sharing, collaboration, critical thinking, discussion, debating, problem-solving, conflict management and resolution, asking questions, listening, perspective taking, and empathy. Communication skills will be needed in the labor market, because jobs will be increasingly social-skills-intensive (ibid.). Innovation and new knowledge are seldom generated by individuals thinking and working alone but rather on the basis of collaboration with others (OECD 2018).

The workplace of the future will include versatile digital environments. Interpersonal communication processes in new digital environments require employees and leaders to develop their knowledge, attitudes, and skills. Timely information sharing, being available remotely, and building and maintaining interpersonal relationships in primarily technologymediated ways are processes that future workers need to be aware of and manage. The future worker will face challenges associated with crossing geographical, temporal, and often cultural 
boundaries as well as using communication technologies to collaborate with colleagues, supervisors, and subordinates.

Learning is crucial for successfully orientating oneself toward future work. Workplace communication can and should be learned and developed. Everyone can improve both their interpersonal communication skills and attitudes, and everyone can acquire knowledge about constructive workplace communication. Yet, communication competence at work is not only an individual resource but also a collective form of competence exhibited by teams, organizations, and networks. In future work, the changing work environments and the intensifying demands of being productive can be managed if the workforce is up to it. Developing communication competence and learning interpersonal skills are vital elements in equipping workers for the future.

\section{References}

Agevall, O. \& Olofsson, G. 2013. The emergence of the professional field of higher education in Sweden. Professions \& Professionalism 3(2), 547.

Amadeo, K. 2019. Universal basic income, its pros and cons with examples. The balance. Available at: www.thebalance.com/universal-basic-income-4160668 (accessed June 17, 2019).

Barile, S., Saviano, M., \& Simone, C. 2015. Service economy, knowledge, and the need for T-shaped innovators. World Wide Web 18, 1177-1197. doi:10.1007/s11280-11014-03050301.

Beans, C. 2018. Inner workings: Can robots make good teammates? Proceedings of the National Academy of Sciences 115(44), 11106-11108.

Bennett, S., Maton, K., \& Kervin, L. 2008. The “digital natives” debate: A critical review of the evidence. British Journal of Educational Technology 39(5), 775-786. doi:10.1111/ j.1467-8535.2007.00793.x.

Brante, T. 2013. The professional landscape: The historical development of professions in Sweden. Professions \& Professionalism 3(2), 558. doi:10.7577/pp.558.

de Graaf, M. M. A., Allouch, S. B., \& Klamer, T. 2015. Sharing a life with Harvey: Exploring the acceptance of and relationship-building with a social robot. Computers in Human Behavior 43, 1-14.

Dent, M., Bourgeault, I. L., Denis, J.-L., \& Kuhlmann, E. 2016. General introduction: The changing world of professions and professionalism. In M. Dent, I. L. Bourgeault, J.-L. Denis, 
\& E. Kuhlmann (Eds.) The Routledge companion to the professions and professionalism. London: Routledge, 1-10.

Edwards, A., Edwards, C., Westerman, D., \& Spence, P. R. 2019. Initial expectations, interactions, and beyond with social robots. Computers in Human Behavior 90, 308-314.

Edwards, C., Edwards, A., Spence, P. R., \& Westerman, D. 2016. Initial interaction expectations with robots: Testing the human-to-human interaction script. Communication Studies 67(2), 227-238. doi:10.1080/10510974.2015.1121899.

Estlund, C. 2018. What should we do after work? Automation and employment law. Yale Law Journal 128(2), 254-326.

Eurofound. 2015. Sustainable work over the life course: Concept paper. Luxembourg: Publications Office of the European Union. Available at:

www.eurofound.europa.eu/sites/default/files/ef_publication/field_ef_document/ef1519en.pdf (accessed January 27, 2019).

Eurofound. 2018. Employment and working conditions of selected types of platform work. Luxembourg: Publications Office of the European Union. Available at:

www.eurofound.europa.eu/sites/default/files/ef_publication/field_ef_document/ef18001en. pdf (accessed January 27, 2019).

Eurofound and the International Labour Office. 2017. Working anytime, anywhere: The effects on the world of work. Luxembourg: Publications Office of the European Union, and Geneva: The International Labour Organization. Available at: www.eurofound. europa.eu/sites/default/files/ef_publication/field_ef_document/ef1658en.pdf (accessed January 27, 2019).

Evetts, J. 2011. Sociological analysis of professionalism: Past, present and future. Comparative Sociology 10, 1-37. doi:10.1163/156913310X522633.

Fonner, K. L. \& Roloff, M. E. 2012. Testing the connectivity paradox: Linking teleworkers' communication media use to social presence, stress from interruptions, and organizational identification. Communication Monographs 79(2), 205-231.

Ghobadi, S. \& D’Ambra, J. 2011. Coopetitive knowledge sharing: An analytical review of literature. Electronic Journal of Knowledge Management 9(4), 307-317. Available at: www. ejkm.com/volume9/issue4 (accessed February 18, 2019).

Gibbs, J. L., Rozaidi, N. A., \& Eisenberg, J. 2013. Overcoming the “ideology of openness”: Probing the affordances of social media for organizational knowledge sharing. Journal of Computer-Mediated Communication 19(1), 102-120.

Gnambs, T. \& Appel, M. 2019. Are robots becoming unpopular? Changes in attitudes towards autonomous robotic systems in Europe. Computers in Human Behavior 93, 53-61.

Guest, D. 1991. The hunt is on for the Renaissance man of computing. The Independent September 17. 
Harwood, J. 2017. Intergroup contact. In Oxford research encyclopedia of communication. New York: Oxford University Press. doi:10.1093/acrefore/9780190228613.013.429.

Healy, J., Nicholson, D., \& Parker, J. 2017. Guest editors’ introduction: Technological disruption and the future of employment relations. Labour and Industry 27(3), 157-164. doi:10.1080/10301763.2017.1397258.

Hearn, J., Biese, I., Choroszewicz, M., \& Husu, L. 2016. Gender, diversity and intersectionality in professions and potential professions: Analytical, historical and contemporary perspectives. In M. Dent, I. L. Bourgeault, J.-L. Denis, \& E. Kuhlmann (Eds.) The Routledge companion to the professions and professionalism. London: Routledge, 5770 .

Ing, D. 2008. T-shaped professionals, T-shaped skills, hybrid managers. Available at: https://coevolving.com/blogs/index.php/archive/t-shaped-professionals-t-shaped-skillshybrid-managers/ (accessed February 2, 2019).

Kaplan, A. \& Haenlein, M. 2019. Siri, Siri, in my hand: Who's the fairest in the land? On the interpretations, illustrations, and implications of artificial intelligence. Business Horizons 62(1), 15-25.

Khosla, R., Nguyen, K., \& Chu, M.-T. 2017. Human-robot engagement and acceptability in residential aged care. International Journal of Human-Computer Interaction 33(6), 510-522.

Kilpi, E. (Ed.) 2016. Perspectives on new work: Exploring emerging conceptualizations, 2nd ed. Helsinki: Sitra. Available at: https://media.sitra.fi/2017/02/28142631/Selvityksia114.pdf (accessed February 5, 2019).

Leite, I., Pereira, A., Mascarenhas, S., et al. 2013. The influence of empathy in human-robot relations. International Journal of Human-Computer Studies 71(3) 250-260.

Levin-Waldman, O. M. 2018. The inevitability of a universal basic income. Challenge 61(2), 133-155. doi:10.1080/05775132.2018.1454382.

McKinsey Global Institute. 2017. A future that works: Automation, employment, and productivity. Available at: https://perma.cc/X9BX-9RWQ (accessed January 13, 2019).

Moore, C. 2016. The future of work: What Google shows us about the present and future of online collaboration. TechTrends 60, 233-244. doi:10.1007/s11528-11016-0044-0045.

Morikawa, M. 2017. Firms' expectations about the impact of AI and robotics: Evidence from a survey. Economic Inquiry 55(2), 1054-1063.

Nass, C. \& Moon, Y. 2000. Machines and mindlessness: Social responses to computers. Journal of Social Issues 56(1), 81-103.

OECD. 2018. The future of education and skills 2030. Available at: www.oecd.org/education/2030/E2030\%20Position\%20Paper\%20 (5 April 2018). (accessed March 29, 2019). 
O’Leary, M. B., Mortensen, M., \& Woolley, A. W. 2011. Multiple team membership: A theoretical model of its effects on productivity and learning for individuals and teams. Academy of Management Review 36(3), 461-478.

Phillips, A. 2018. How has AI changed the way humans communicate? Available at: https://becominghuman.ai/how-has-ai-changed-the-way-humans-communicate-10369fc2453a (accessed February 12, 2019).

Piçarra, N. \& Giger, J.-C. 2018. Predicting intention to work with social robots at anticipation stage: Assessing the role of behavioral desire and anticipated emotions. Computers in Human Behavior 86, 129-146.

Quadflieg, S., Ul-Haq, I., \& Mavridis, N. 2016. Now you feel it, now you don't: How observing human-robot interactions and human-human interactions can make you feel eerie. Interaction Studies 17(2), 211-247. doi:10.1075/is.17.2.03qua.

Qureshi, A. H., Nakamura, Y., Yoshikawa, Y., \& Ishiguro, H. 2018. Intrinsically motivated reinforcement learning for human-robot interaction in the real-world. Neural Networks 107, 23-33.

Reeves, B. \& Nass, C. 1996. The media equation: How people treat computers, television, and new media like real people and places. Stanford, CA: CSLI Publications.

Robots and the workplace of the future. 2018. Positioning paper. Frankfurt, Germany: International Federation of Robotics. Available at: https://ifr.org/downloads/papers/ IFR_Robots_and_the_Workplace_of_the_Future_Positioning_Paper.pdf (accessed June 18, 2019).

Ruppel, C. P., Gong, B., \& Tworoger, L. C. 2013. Using communication choices as a boundary-management strategy: How choices of communication media affect the work-life balance of teleworkers in a global virtual team. Journal of Business and Technical Communication 27(4), 436-471.

Savela, N., Turja, T., \& Oksanen, A. 2018. Social acceptance of robots in different occupational fields: A systematic literature review. International Journal of Social Robotics 10(4), 493-502.

Sivunen, A. \& Valo, M. 2010. Communication technologies. In R. Ubell (Ed.) Virtual teamwork: Mastering the art and practice of online learning and corporate collaboration. Hoboken, NJ: John Wiley \& Sons, Inc., 137-157.

Stoll, B., Edwards, C., \& Edwards, A. 2016. “Why aren’t you a sassy little thing”: The effects of robot-enacted guilt trips on credibility and consensus in a negotiation. Communication Studies 67(5), 530-547. doi:10.1080/10510974.2016.1215339.

The Millennium Project. 2019. Three future work/technology 2050 global scenarios. Available at: www.millennium-project.org/future-work-technology-2050-global-scenarios/ (accessed February 5, 2019). 
Vlachos, E., Jochum, E., \& Demers, L.-P. 2016. The effects of exposure to different social robots on attitudes toward preferences. Interaction Studies 17(3), 390-404.

doi:10.1075/is.17.3.04vla.

Vogd, W. 2017. The professions in modernity and the society of the future: A theoretical approach to understanding the polyvalent logics of professional work. Professions \& Professionalism 7(1), 1611.

World Economic Forum. 2016. New vision for education: Fostering social and emotional learning through technology. Available at:

www3.weforum.org/docs/WEF_New_Vision_for_Education.pdf (accessed March 29, 2019).

World Economic Forum. 2018. The future of jobs report. Available at:

www3.weforum.org/docs/WEF_Future_of_Jobs_2018.pdf (accessed January 17, 2019). 